\title{
Responsiveness Improvement of Idling Speed Control for Automotive Using SMC
}

\author{
Yang ZHANG ${ }^{1}$, Nobuo KURIHARA ${ }^{2}$, Hiroyuki YAMAGUCHI ${ }^{3}$ \\ ${ }^{1}$ Doctor of Science Program in Mechanical Systems, Hachinohe Institute of Technology, Hachinohe, Japan; ${ }^{2}$ Graduate School of \\ Engineering, Hachinohe Institute of Technology, Hachinohe, Japan; ${ }^{3}$ Department of System and Information, Hachinohe Institute of \\ Technology, Hachinohe, Japan. \\ Email: kurihara@hi-tech.ac.jp
}

Received August $8^{\text {th }}, 2009$; revised September $8^{\text {th }}, 2009$; accepted September $15^{\text {th }}, 2009$.

\begin{abstract}
To improve the responsiveness of engine speed control to disturbances, robust controls were investigated by simulation. The intake air control system of a gasoline engine is a typical nonlinear system, and the disturbances and parameter perturbations are generally regarded as being the unstable factors with regard to engine control. In this paper, a Mean-Value Engine Model (MVEM) with disturbances and parameter perturbations is investigated using Sliding Mode Control (SMC), which is a form of variable structure control, with a view to address instability in the idle speed control process. The simulation results confirmed that, compared with a conventional PI (Proportional-Integral) controller, the stability of the idle speed for an engine that is being subjected to disturbances, parameter variations and background noise is greatly improved by the application of SMC.
\end{abstract}

Keywords: Gasoline Engine, Intake Air Control, Sliding Mode Control, Simulation

\section{Introduction}

Since the beginning of the 21 st century, environmental and energy problems have been becoming increasingly serious. A lack of fuel economy for automobiles is considered to be the main cause of the global energy crisis, and this issue needs to be addressed. Idle speed is the minimum operating speed of a combustion engine [1]. The period at idle occupies $30 \%$ of driving time for urban traffic. Furthermore, if the idle speed can be reduced to $100 \mathrm{rpm}$ (revolutions per minute) by improving the control method, fuel consumption will be reduced by 2 to $5 \%$. Therefore, significant fuel economy and emissions improvements can be achieved by lowering the idle speed of an engine. In order to achieve a relatively lower idle speed while at the same time preventing the engine from stalling, it is necessary to maintain a stable idle speed in the presence of both known disturbances (e.g. stationary steering and evaporation-gas purge) and unknown disturbances. The automotive engine is a typical nonlinear, time-delay, time-varying parameter system. Recently there are many studies that apply control theories such as LQG, PID, and adaptive control to idle-speed control [2]. In particular, because Variable structure control is suitable for linear and nonlinear, continual and discrete, certain and uncertain systems, the application of sliding mode control is regarded as the solution to the problem of improving the idle-speed control. Nevertheless there are some studies are applying this theory $[3,4]$. However, idle-speed control is supposed to be investigated practically.

In this paper, idle speed control was studied based on a non-linear gasoline engine model. As the PID (proportional-integral-derivative) controller is usually used for idle speed control, the PID control and sliding mode control (SMC) were employed to improve idle-speed control. The several disturbances such as control input disturbance, torque disturbance and fuel disturbance were added in the engine model to certify the responsiveness and stability of two control methods. And the operation of the sudden start also was also studied under the fuel disturbance. The system is simulated by MATLAB /Simulink. Relying on result of simulations, the robustness of idle-speed control was improved by using SMC.

\section{Idle Speed Control System}

In this paper, we used an idle speed control system which was built based on the mean value engine model (MVEM) [5]. The model consists of three units: an intake manifold unit, a fuel mass unit, and a crankshaft unit. Because idle speed control is the subject of this study, an electronic 


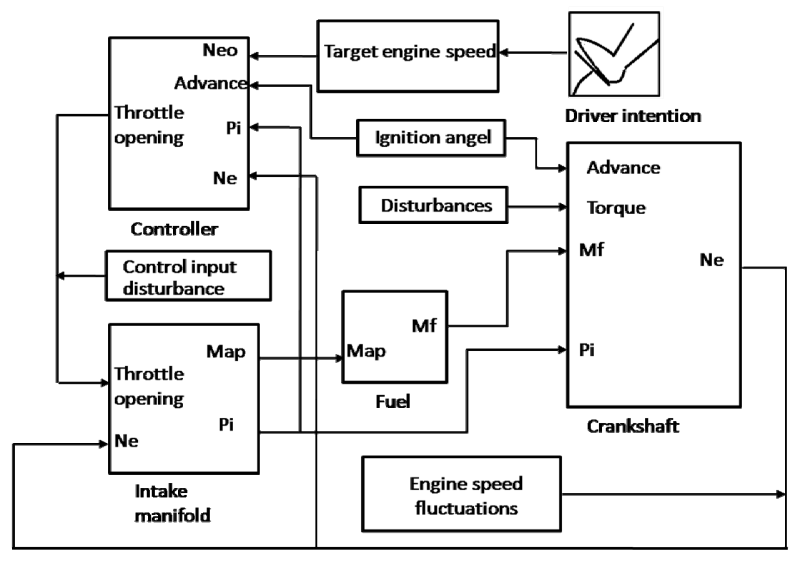

Figure 1. Engine model for idle speed system

throttle is necessary. The usual control process for idle speed is illustrated as follows. The intake air flow is adjusted to achieve the set point for the engine speed by adjusting the angle and position of the electronic throttle. The crank angle sensor detects the engine speed, and the angle of the electronic throttle depends on the controller in the engine control unit. Next, the amount of air supplied to the cylinder is adjusted using the electronic throttle. Once that has been done, an amount of fuel proportionate to the air flow is injected into the cylinder. Thus, the torque produced by fuel combustion maintains a constant engine speed. A model of an idle speed control system is shown in Figure 1.

Next, we will describe the three parts of the engine model by providing the equations we used. The main initial parameters of the engine model were as follows: the engine displacement $\left(V_{d}\right)$ is $1.3 \mathrm{~L}$; the fuel energy constant $\left(H_{u}\right)$ was $43000 \mathrm{~K} \mathrm{~J} / \mathrm{kg}$; the gas constant of air $(R)$ was $0.00287 \mathrm{~m} 2 \mathrm{bar} / \mathrm{k} . \mathrm{kg}$; the atmospheric temperature $\left(T_{a}\right)$ was $293 \mathrm{~K}$; the intake manifold volume $V_{i}$ was $0.000564 \mathrm{~m}^{3}$ the atmospheric pressure $\left(P_{a}\right)$ was $1.013 \mathrm{bar}$; and the moment of engine inertia was $5.2638 \mathrm{kgm}^{2}$. Here we considered four factors that can easily make idle speed control unstable: torque disturbance, fuel vapor disturbance, control input disturbance, and parameter errors.

\subsection{Crankshaft Block}

$$
\dot{n}=H_{u} \eta_{i} \dot{m}_{f} / \operatorname{In}-\left(P_{f}+P_{p}+P_{d}\right) / I n
$$

The variable $\mathrm{n}$ in Equation (1) is the engine speed (the unit used was set at $\mathrm{rpm} / 1000) ; \eta_{i}$ is the thermal efficiency; and $P_{f}, P_{p}$ and $P_{b}$ are frictional power, pumping power, and load power, respectively.

$$
\begin{aligned}
& \eta_{i}=\eta_{n} \eta_{p} \eta_{\lambda} \eta_{\theta} \\
& \eta_{n}=-0.015+0.558\left(1-0.392 / n^{036}\right)
\end{aligned}
$$

$$
\begin{aligned}
& \eta_{p}=0.827+0.528 P_{i}-0.392 P_{i}^{2} \\
& \eta_{\lambda}=-0.0171+1.74 \lambda-0.745 \lambda^{2} \\
& \eta_{\theta}=0.7+0.024\left(\theta-\theta_{m b t}\right)-0.00048\left(\theta-\theta_{m b t}\right)^{2}
\end{aligned}
$$

$P_{f}, P_{p}$ and $P_{b}$ are calculated using the three empirical equations below.

$$
\begin{aligned}
& P_{f}=1.673 n+0.272 n^{2}+0.0135 n^{3} \\
& P_{p}=-0.969 n P_{i}+0.206 n^{2} P_{i} \\
& P_{b}=M_{b} n(2 \pi / 60)=K_{b} n^{3}
\end{aligned}
$$

Here, $P_{i}$ is the manifold pressure; $\theta$ is the ignition angle; $\theta_{m b t}$ is the mean best torque spark advance; $\lambda$ is the excess air coefficient; and $M b$ and $K_{b}$ are both for the torque load.

\subsection{Fuel Block}

$$
\begin{aligned}
& \ddot{m}_{f f}=\left(X \cdot \dot{m}_{f i}-\dot{m}_{f f}\right) / \tau_{f} \\
& \dot{m}_{f v}=(1-X) \dot{m}_{f i} \\
& X=-0.227 P_{i}-0.055 n+0.68 \\
& \tau_{f}=1.35(-0.0672 n+1.68)\left(P_{i}-0.825\right)^{2}+(-0.06 n+0.15)+0.56
\end{aligned}
$$

Here, $\ddot{m}_{f f}$ is the evaporation fuel in the cylinder; $\dot{\mathrm{m}}_{\mathrm{fi}}$ is the injected fuel; $\dot{m}_{f v}$ is the gasified fuel; $\dot{\mathrm{m}}_{\mathrm{f}}$ is the total amount of fuel in the cylinder; $X$ is the coefficient of the fuel deposit; and $\tau_{f}$ is the time constant for fuel evaporation.

\subsection{Manifold Block}

$$
\dot{P}_{i}=R T_{i}\left(\dot{m}_{a t}-\dot{m}_{a p}\right) / V_{i}+P_{i} \dot{T}_{i} / T_{i}
$$

Here, $T_{i}$ is the temperature in the manifold; $\dot{m}_{a t}$ is the intake air which passes through the throttle; and $\dot{m}_{a p}$ is the cylinder intake air.

$$
\dot{m}_{a t}=\dot{m}_{i s}+\dot{m}_{a i}
$$

where $\dot{m}_{i s}$ is the intake air that passes through the by-pass valve

$$
\dot{m}_{a i}=0.3988 \cdot \beta_{1}\left(u_{\theta}\right) \cdot \beta_{2}\left(P_{r}\right)-0.01
$$

Here, $\dot{m}_{a i}$ is the intake air that passes through the throttle.

$$
\begin{gathered}
\beta_{1}\left(u_{\theta}\right)=1-1.4073 \cos \left(u_{\theta} \pi / 180\right)+0.4087 \cos ^{2}\left(u_{\theta} \pi / 180\right) \\
\beta_{2}\left(P_{r}\right)=\left\{\begin{array}{cl}
\sqrt{1-\left(\frac{P_{r}-0.4125}{1-0.4125}\right)^{2}} & P_{r} \geq 0.4125 \\
0 & P_{r}<0.4125
\end{array}\right.
\end{gathered}
$$


Here, $\mathrm{u}_{\theta}$ is the opening of the throttle and $P_{r}$ is the ratio of $P_{i}$ to $P_{a}$.

Where $\eta_{v}$ is the engine volumetric efficiency.

$$
\begin{aligned}
& \eta_{v}=0.952-0.075 / P_{i} \\
& \dot{T}_{i}=R \cdot\left[-\left(0.4 \dot{m}_{a p}+\dot{m}_{a t} T_{i}^{2}\right)+1.4 \dot{m}_{a t} T_{a} T_{i}\right] / P_{i} V_{i}
\end{aligned}
$$

\section{Linearization}

As is well known, the engine model is a typical noninear system. For the following design for SMC, we needed to linearize the engine model to a state-space equation at the operation point. In this case, we selected an engine speed of $\mathrm{n}$ and manifold pressure of $P_{i}$ as two states. Here, $u_{\varphi}$ is the input of advance angle ignition and $u_{\theta}$ is the input of the throttle, and both were provisionally considered as control inputs.

$$
\begin{aligned}
& x=\left[\begin{array}{l}
x_{1} \\
x_{2}
\end{array}\right]=\left[\begin{array}{l}
n \\
P_{i}
\end{array}\right] \quad u=\left[\begin{array}{l}
u_{\varphi} \\
u_{\theta}
\end{array}\right] \\
& A(x)=\left[\begin{array}{l}
A_{1}(x) \\
A_{2}(x)
\end{array}\right] \quad B(x)=\left[\begin{array}{cc}
B_{1}(x) & 0 \\
0 & B_{2}(x)
\end{array}\right] \\
& \dot{x}=A(x)+B(x) u \\
& A_{1}(x)=0.1841 P_{i}-0.039 n P_{i}-0.3178-0.0516 n-0.0026 n^{2} \\
& A_{2}(x)=61.895 \beta_{1} \beta_{2}-18 n P_{i}-15.52-1.397 n \\
& B_{1}(x)=\eta_{n} \eta_{p} \dot{m}_{a p} \cdot 680.7 / n \quad B_{2}(x)=R T_{i} / V
\end{aligned}
$$

Having sorted out the affine non-linear equations as stated above, we then addressed the target operation point $\left(x_{d}\right)$, which is given as follows:

$$
x_{d}=\left[\begin{array}{l}
n_{d} \\
P_{i d}
\end{array}\right]
$$

Therefore, the engine model is linearized in the vicinity of $x_{d}$.

$$
\begin{aligned}
\tilde{x} & =x-x_{d} \quad \tilde{u}=u-u_{d} \quad \dot{\tilde{x}}=A \tilde{x}+B \tilde{u} \\
A & =\left[\begin{array}{ll}
a_{11} & a_{12} \\
a_{21} & a_{22}
\end{array}\right] \quad B=\left[\begin{array}{ll}
b_{11} & b_{12} \\
b_{21} & b_{22}
\end{array}\right]
\end{aligned}
$$

Next, we substituted the tangent line for the curved line according to the affine non-linear equation.

$$
A=\left.\frac{\partial f}{\partial x}\right|_{x_{d}, u_{d}}=\left(\begin{array}{ccc}
\frac{\partial f_{1}}{\partial x_{1}} & \cdots & \frac{\partial f_{1}}{\partial x_{n}} \\
\vdots & \ddots & \vdots \\
\frac{\partial f_{n}}{\partial x_{1}} & \cdots & \frac{\partial f_{n}}{\partial x_{n}}
\end{array}\right)
$$

$$
\begin{aligned}
& B=\left.\frac{\partial f}{\partial u}\right|_{x_{d}, u_{d}}=\left(\begin{array}{ccc}
\frac{\partial f_{1}}{\partial u_{1}} & \cdots & \frac{\partial f_{1}}{\partial u_{n}} \\
\vdots & \ddots & \vdots \\
\frac{\partial f_{n}}{\partial u_{1}} & \cdots & \frac{\partial f_{n}}{\partial u_{n}}
\end{array}\right) \\
& a_{11}=-0.039-0.0516-0.0052 n_{d} \\
& a_{12}=-0.1841-0.0039 n_{d} \\
& a_{21}=-0.039-0.0516-0.0052 n_{d} \\
& a_{22}=\left.61.895 \cdot \frac{\partial \beta_{2}}{\partial P_{i}}\right|_{x_{d}}-18 n_{d} \\
& b_{12}=b_{21}=0 \\
& b_{12}=\eta_{n} \eta_{p} \dot{m}_{a p} \cdot 680.7 / n \\
& b_{22}=1552
\end{aligned}
$$

As a result, we were able to obtain the final matrices for $\mathrm{A}$ and $\mathrm{B}$ of the linearized model at two certain values of the abovementioned states.

\section{PID Control Design}

In the paper, we employed PI controller shown in Figure 2. The gain of $K p$ and $K i$ are determined by the ZieglerNichols method.

\section{Sliding Mode Control Design}

SMC is a type of variable structure control in which the dynamics of a nonlinear system are altered by the application of a high-frequency switching control [6]. In other words, SMC uses practically infinite gain to force the trajectories of a dynamic system to slide along the restricted sliding mode subspace. This is an important, robust control approach that provides an adaptive approach to tackling the parametric system, uncertain parametric system, and uncertain disturbance system. If a switching surface is appropriately designed with desirable characteristics, the system will exhibit desirable behavior when confined to this switching surface. To pursue the target value, idle-speed control can be shown as a servo system. Thus, the sliding mode for a single-input single-output

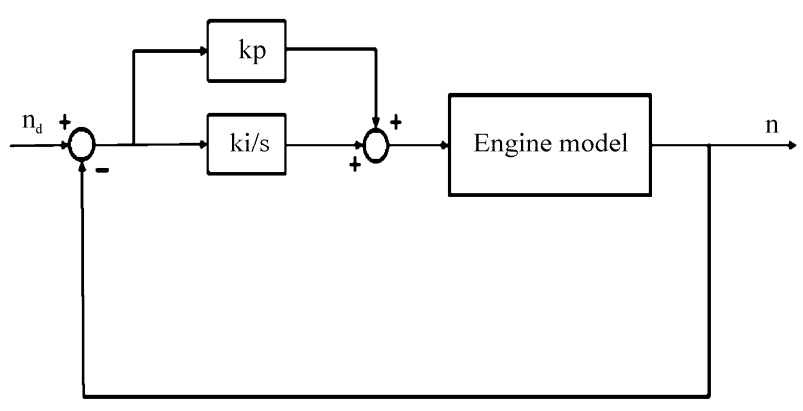

Figure 2. Block diagram of PI controller 


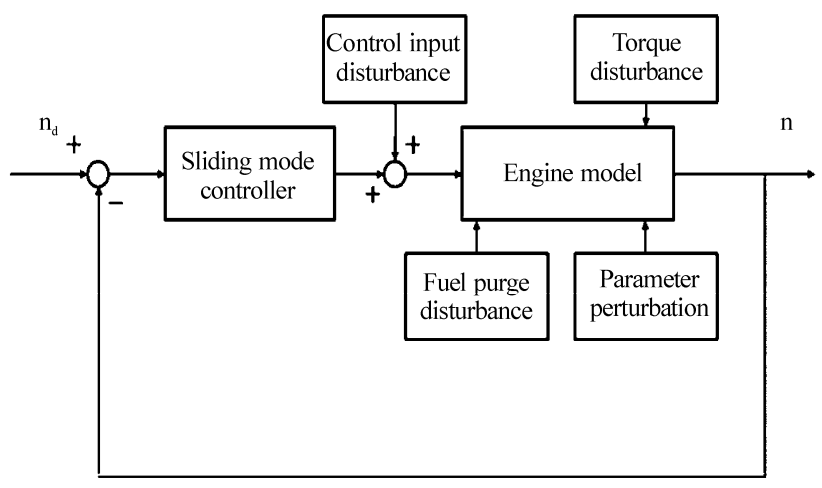

Figure 3. Block diagram of SMC

system has been made into the block diagram shown in Figure 2, which illustrates a closed-loop SMC. The control input is the sum of the linear and non-linear inputs. Here, $n_{d}$ is the target engine speed, $n$ is the actual engine speed, and the four kinds of disturbances we have considered in this paper have also been added in the Figure 3.

\subsection{Controller}

In this paper, we are only considering the angle of the throttle as the control input. Consequently, the following system is considered.

$$
\begin{aligned}
{\left[\begin{array}{l}
\dot{x}_{1} \\
\dot{x}_{2}
\end{array}\right] } & =\left[\begin{array}{ll}
a_{11} & a_{12} \\
a_{21} & a_{22}
\end{array}\right]\left[\begin{array}{l}
x_{1} \\
x_{2}
\end{array}\right]+\left[\begin{array}{l}
b_{12} \\
b_{22}
\end{array}\right] u_{\theta} \\
& =\left[\begin{array}{ll}
a_{11} & a_{12} \\
a_{21} & a_{22}
\end{array}\right]\left[\begin{array}{l}
n \\
P_{i}
\end{array}\right]+\left[\begin{array}{l}
b_{12} \\
b_{22}
\end{array}\right] u_{\theta}
\end{aligned}
$$

In order to apply SMC to the servo system, an expansion system is used in which a new state, $\mathrm{z}$, is assumed as the value for the integration of the difference between the target value and input. The variable $\mathrm{z}$ is defined in Equation (13) below.

$$
\dot{z}=r-x_{1}=n_{d}-n
$$

The expansion servo system is given in Equation (14) below.

$$
\left[\begin{array}{l}
\dot{z} \\
\dot{x}_{1} \\
\dot{x}_{2}
\end{array}\right]=\left[\begin{array}{ccc}
0 & -1 & 0 \\
0 & a_{11} & a_{12} \\
0 & a_{21} & a_{22}
\end{array}\right]\left[\begin{array}{l}
z \\
x_{1} \\
x_{2}
\end{array}\right]+\left[\begin{array}{l}
0 \\
0 \\
b_{22}
\end{array}\right] u+\left[\begin{array}{l}
1 \\
0 \\
0
\end{array}\right] r
$$

Equation (14) can be rewritten as follows:

$$
\dot{x}=A x+B u+E r
$$

The switching function is as follows:

$$
\sigma(x)=S x=S *\left[\begin{array}{l}
z \\
x_{1} \\
x_{2}
\end{array}\right]
$$

The design for the switching surface is described late. When the system is in sliding mode, the switching function is as follows:

$$
\sigma(x)=0
$$

When the system is in sliding mode state, the dynamic characteristic is exhibited. When above the switching hyper-plane, the system maintains $\sigma=\dot{\sigma}=0$. Hence, by using $\dot{\sigma}=S \dot{x}$, substituting Equation (15) into $\dot{\sigma}=0$ gives:

$$
0=S A x+S B u_{e q}+S E \theta_{r}
$$

Taking the control law as:

$$
u_{e q}=-(S B)^{-1}\left(S A x+S E \theta_{r}\right)
$$

Equation (19) gives the equivalent linear control of a servo system with sliding mode.

\subsection{Hyper-Plane}

For the system stability margin, the switching hyperplane $\mathrm{S}$ is given as follows:

$$
S=B^{T} P
$$

where $\mathrm{P}$ is the positive definite solution of the Riccati equations, so that:

$$
\begin{aligned}
& P A_{\varepsilon}+A_{\varepsilon}^{T} P-P B B^{T} P+Q=0 \\
& A_{\varepsilon}=A+\varepsilon I
\end{aligned}
$$

Where $\varepsilon$ is the stability margin coefficient, $\varepsilon>0$ is assumed.

To determine the switching law, the Lyapunov function candidate with $\sigma$ is defined as follows:

$$
V=\frac{1}{2} \sigma(x)^{2}
$$

If the first-order derivative $\mathrm{V}$ of the Lyapunov function is a negative definite function, $\sigma$ can converge to 0 . So the control input is the sum of the linear and non-linear inputs.

$$
u=u_{e q}+u_{n l}
$$

Here, non-linear input $\mathrm{u}_{\mathrm{nl}}$ is obtained as follows:

$$
u_{n l}=-k \frac{\sigma}{|\sigma|+\eta}(S B)^{-1}
$$

If $k>0, \eta>0, \mathrm{k}$ is the non-linear input switching gain and it is efficient in compensating for unknown disturbances. To alleviate chatter in the control output of the sliding mode controller, we used $\frac{\sigma}{|\sigma|+\eta}$ as the output alteration, which is generally called the smooth function 
for replacing a conventional signal function.

$$
\dot{V}=\sigma \dot{\sigma}=-k \frac{\sigma^{2}}{|\sigma|+\eta}<0
$$

According to Lyapunov's second theorem on stability, the hyper-plane measures the existence of the sliding mode and reachability.

\section{Simulation}

In order to confirm robustness with respect to a load change disturbance during idle speed, the system was simulated under the conditions below.

First, the initial idle speed of the engine was $700 \mathrm{rpm}$, given the existence of disturbances such as fuel purges and power window, a unit step input was added for the disturbance that results from an evaporation-gas purge in the fuel module and another unit step input was added for the disturbance that results from stationary steering or other types of torque variations in the crankshaft module. The simulation results are shown in Figure 4.

Second, we considered the variable factors in a real engine, allowing us to input the engine model error, the
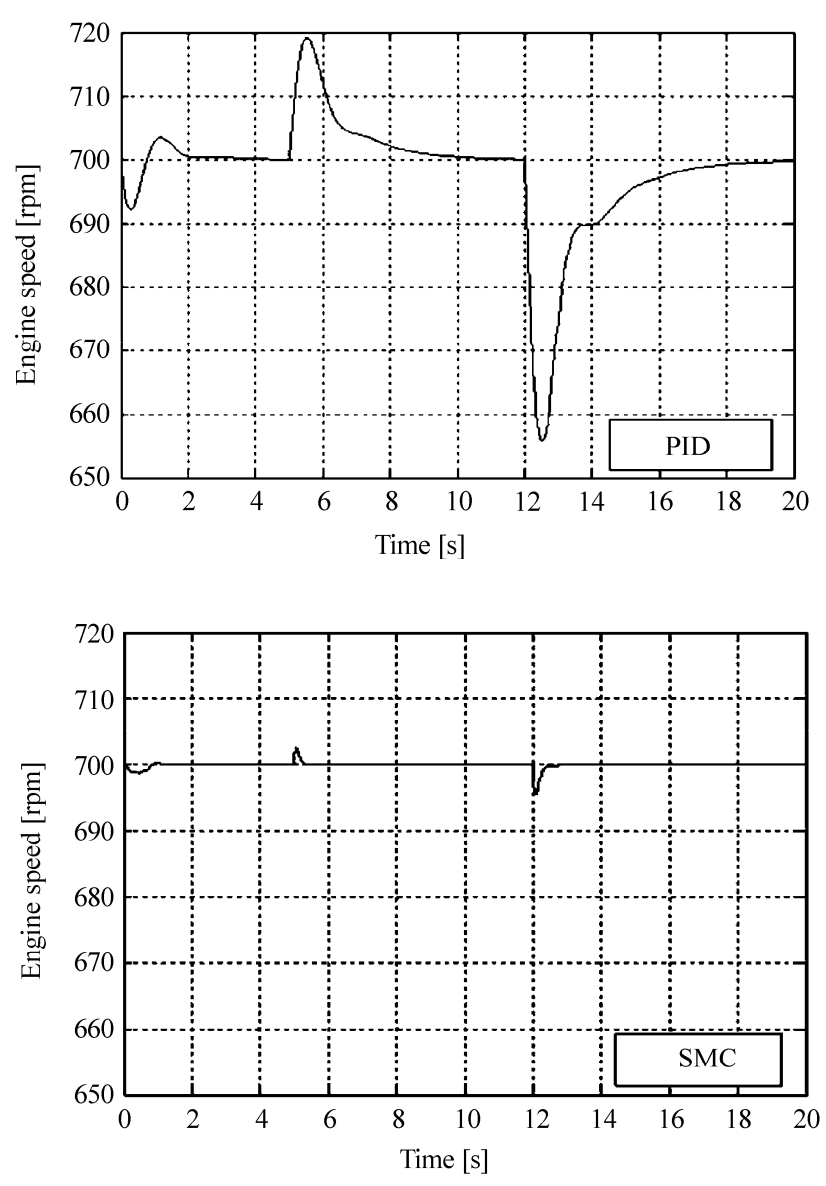

Figure 4. Responses for two disturbances
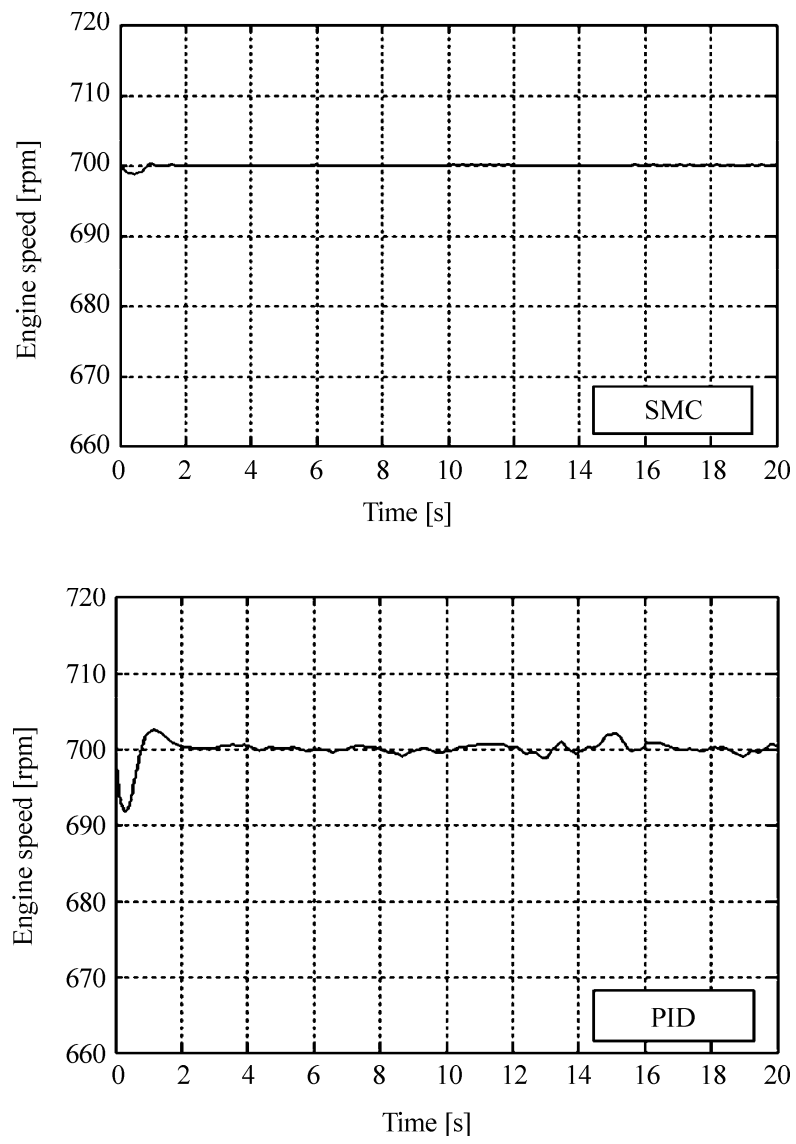

Figure 5. Responses for input error and parameter perturbations

control input error, the ignition angle error, and the $\mathrm{A} / \mathrm{F}$ (air/fuel) ratio into the engine model. Figure 5 shows the results.

From Figure 4, we can see that if two identical disturbances are loaded at 5 seconds and 12 seconds, the control system is forced to spend a considerable amount of time reaching the target speed again when PID is used. In other words, the response time is long and the compensation effect is weak. In contrast, the disturbances were almost compensated for because of the relatively large value of the compensating gain $\mathrm{k}$ we used in the nonlinear input.

$\mathrm{A} \pm 3 \%$ random error was added in front of the engine model as a control input error. In addition, $\pm 3 \%$ and $\pm 1 \%$ random errors were added to the stoichiometric fuel air ratio and the ignition angle, respectively. The results were as follows. From Figure 5, we can see that there is little fluctuation when PID is used, and the use of SMC does not change the results.

Third, Moreover, as background noise, the engine speed fluctuations measured on an actual engine was added to the engine model, meanwhile, two disturbances as same as those in Figure 4 were loaded. The simulation result is 
shown in Figure 6. The control system with the sliding mode controller is clearly more effective against both of the two disturbances as if background noise was loaded.

Finally, we considered the responsiveness and tracing ability when the engine is made a sudden start from a lower idle speed to a higher speed such as 2000rpm. As far as we know, there is usually little fuel loss in the sudden start condition due to some of fuel drops attached to the manifold, which sometimes leads to the undesirable speed down. So we assumed the sudden start occurred at 6 seconds and a step disturbance as fuel loss was load at the time. The simulation results are shown in Figure 7. Apparently, the transition of the sudden start by SMC is faster than that by PI although the disturbance is loaded.

Based on the aforementioned simulation results, we can see that a control system with a sliding mode controller is more effective with respect to either of the two disturbances, as well as to some errors in the actual engine, proving the robustness of SMC. In addition, the tracing ability of idle speed also appears to be improved
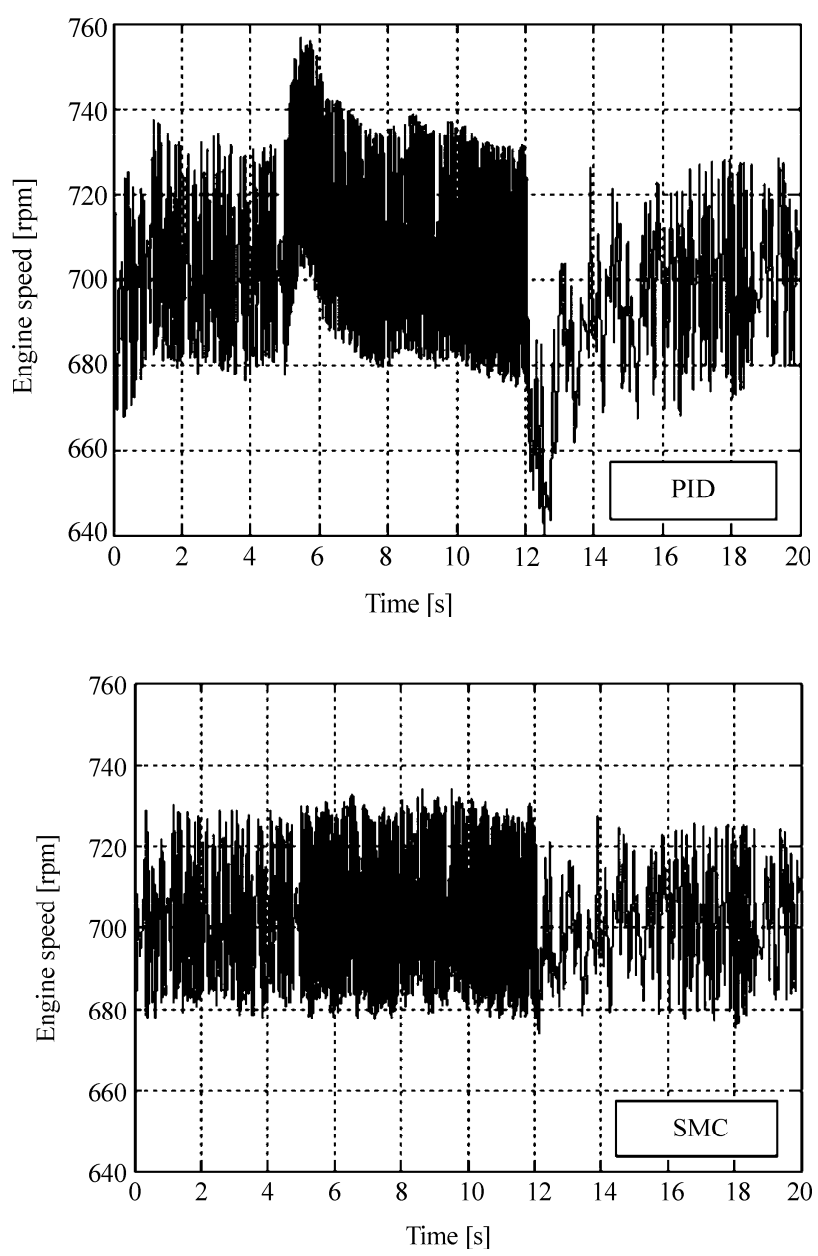

Figure 6. Responses for loading engine-speed signal
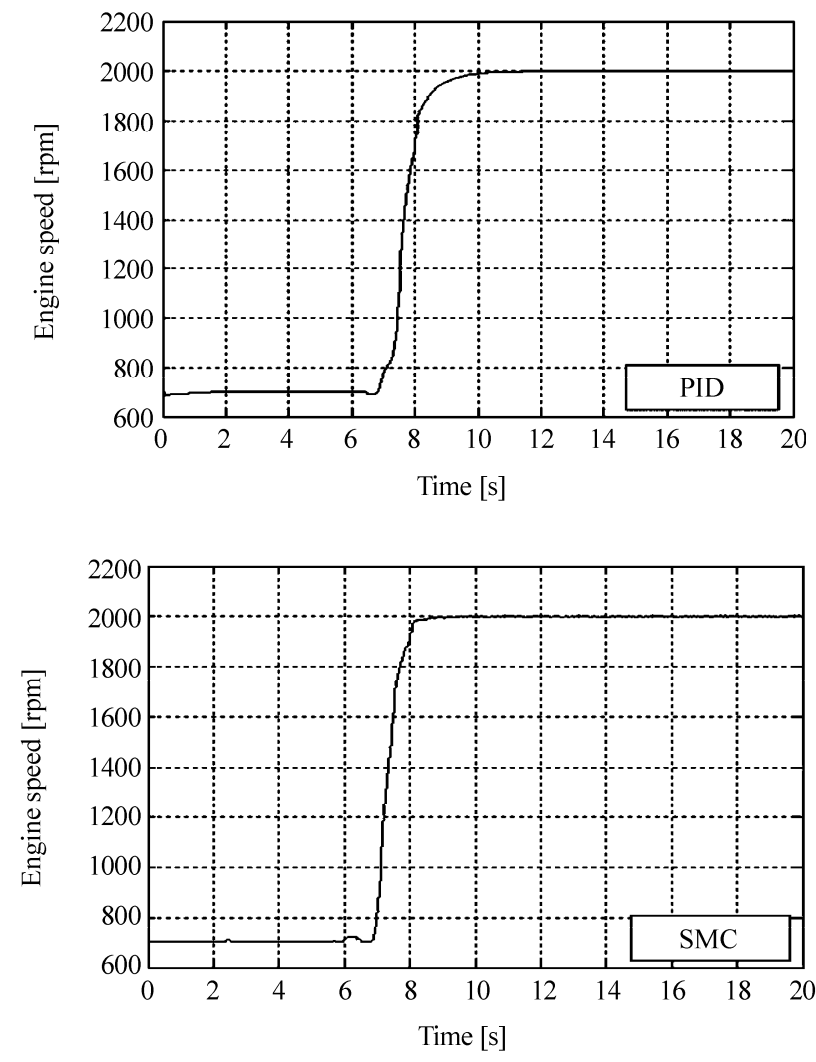

Figure 7. Responses for a sudden start from $700 \mathrm{rpm}$

in the work condition under the sudden start with the fuel disturbance.

\section{Conclusions}

In this paper we addressed the issue of idle speed control in order to improve the stability of an engine's idle speed and improve its fuel economy. To achieve high stability and robustness for the idle speed control system, the electronic throttle (which regulates the intake air flow when an engine is idling) was taken as the control object, the engine was modularized by MATLAB/SIMULINK, and given that the engine system is a typical nonlinear system, the model was linearized at the operating point. Using a linearized state-space model, we built a hyper-plane which is adaptive to the controlled plant, after which we also designed a control input for a controlled plant which is the sum of the nonlinear and linear inputs, so the SMC is constructed in $\mathrm{m}$-file. To produce comparative results, PI control was used, and in accordance with Ziegler-Nichols, the parameters of proportion and integral were adjusted on the initial engine speed of 700 rpm. By using SMC, the switching hyper-plane was designed based on system zeros, and the system was designed as a servo system in order to achieve the target value. Compared with conventional PI control, the stability against disturbances was improved. Furthermore, the 
relative robustness of SMC was confirmed when an engine system was simulated under parameter perturbations and background noise. Above all, it is much more potential to improve idle speed control and pursue low speed of the idle speed by sliding mode control.

\section{REFERENCES}

[1] H. Ando, "Gasoline direct injection engines-present and future," Journal of Software Engineering and Applications, Vol. 53, No. 9, 1999.

[2] F.-C. Hsieh and B.-C. Chen, "Adaptive Idle-speed control for spark-ignition engines,” SAE paper: 011197, 2007.
[3] B. Kwak and Y. Park, "Robust vehicle stability controller based on multiple sliding mode control," SAE paper: 011060, 2001.

[4] Y. Zhang, T. Koorikawa and N. Kurihara, "Evaluation of sliding mode Idle-speed control for SI engines," Journal of Software Engineering and Applications, Vol. 40, No. 4, pp. 997-1002, 2009.

[5] E. Hendricks, A. Chevalier and M. Jansen, et al., "Modeling of the intake manifold filling dynamics [J]," SAE960037, pp. 1-25, 1996.

[6] K. Nonami and H. Tian, "Sliding mode control of nonlinear robust control theory," Chapter 3, Corona publisher, Tokyo, 1994. 